\title{
Safety Review in 10,008 Users of Lansoprazole in Daily Practice
}

\author{
ANGELA A. M. C. CLAESSENS ${ }^{* 1,2}$, EIBERT R. HEERDINK ${ }^{1}$, JACQUES Th. M. VAN EIJK ${ }^{3}$, CORNELIS B. H. W. \\ LAMERS $^{4}$ AND HUBERT G. M. LEUFKENS ${ }^{1}$ \\ ${ }^{1}$ Department of Pharmacoepidemiology and Pharmacotherapy, Utrecht Institute for Pharmaceutical Sciences \\ (UIPS), Utrecht, The Netherlands \\ ${ }^{2}$ Kendle, Utrecht, The Netherlands \\ ${ }^{3}$ Department of Medical Sociology, Health Care Studies, Faculty of Medicine, University of Maastricht, \\ Maastricht, The Netherlands \\ ${ }^{4}$ Department of Gastroenterology, Leiden University, Leiden, The Netherlands
}

\begin{abstract}
SUMMARY
Purpose - Soon after the introduction of the proton pump inhibitor, lansoprazole, a 4-year observational follow-up study was started to evaluate the safety of this drug in naturally-occurring groups of patients in The Netherlands. Results of this study were compared with clinical trial data and the limited published data from observational studies.

Methods - A prospective, observational study in which patients with a new episode of lansoprazole use were followed during the medication period for a maximum of 2 years. All (adverse) events during use were documented by the prescriber, irrespective of possible association with lansoprazole therapy.

Results - A total of 805 general practitioners (GPs) and 266 specialists provided a total of 10,008 lansoprazole users with a broad range of diagnoses. Of all patients, $17.4 \%$ reported one or more adverse events. The profile and frequency of reported adverse events was consistent with results from clinical trials and other observational studies. The most frequently reported adverse events were diarrhoea, headache, nausea, skin disorders, dizziness and generalized abdominal pain/cramps. There was no new evidence of rare adverse events. Furthermore, no lansoprazole-related unlabelled adverse events of clinical significance were recorded.

Conclusions - Although the patterns of use of lansoprazole in daily practice deviated to some extent from the diagnoses in the information leaflet, lansoprazole was found to have a highly acceptable safety profile in this large naturally-occurring group of users. Reporting rates were higher soon after introduction of lansoprazole before falling to a lower stable level. Copyright (C) 2000 John Wiley \& Sons, Ltd.
\end{abstract}

KEY WORDS - lansoprazole; pharmacoepidemiology; safety; adverse events

\section{INTRODUCTION}

Lansoprazole is a proton pump inhibitor introduced on to the Dutch market at the end of 1993

\footnotetext{
* Correspondence to: Angela Claessens MD, Department of Pharmacoepidemiology \& Pharmacotherapy, Utrecht Institute for Pharmaceutical Sciences (UIPS), PO Box 80.082, 3508 TB Utrecht, The Netherlands. Tel: +3130 2537324. Telefax: +31 $302539166 . \quad$ E-mail: claessens.angela@kendle.com or e.r.heerdink@pharm.uu.nl
}

Contract grant sponsor: Hoechst Marion Roussel B.V. indicated for the treatment of reflux oesophagitis and healing of gastric and duodenal ulcers. ${ }^{1}$ Lansoprazole was first introduced as a $30-\mathrm{mg}$ capsule, while in January 1996 a 15-mg capsule was launched for the same diagnoses.

At the time of introduction, lansoprazole had been evaluated in several thousands of patients enrolled in clinical trials. ${ }^{2}$ The most commonly reported adverse events in clinical trials included headache, diarrhoea, nausea, dizziness, vomiting, constipation, asthenia and flatulence. ${ }^{3,4}$ Rarely reported adverse events associated with proton 
pump inhibitors in general were dry mouth, gynaecomastia, acute liver injury, visual disorders and acute polyarthralgia, although regarding the latter two events the relationship with the use of lansoprazole is still under discussion. ${ }^{5-11}$ Besides data from clinical trials, estimates of the 'real-world' safety profile were and still are scarce. ${ }^{12,13}$

Spontaneous case reports stem from undefined, exposed populations, in which data was collected in a non-standardized manner. Epidemiological studies provide more reliable measures of risk and can place spontaneous reports in perspective. ${ }^{14}$ This was one of the reasons for setting up a large epidemiological prospective follow-up study of lansoprazole users in daily clinical practice in The Netherlands with the aim of assessing the safety, efficacy and pattern of use of lansoprazole. The study started directly after the introduction of the drug on to the market. The general results of the first 2 years of this study are described elsewhere. ${ }^{15}$ In this article we focus on the reporting of adverse events during lansoprazole use by a large group of patients found in daily clinical practice, including patients of any age with various diagnoses and underlying diseases. As described by Weber, higher spontaneous reporting rates exist soon after the initial marketing of a drug and this pattern persists for about 2 years before falling to a stable lower level. ${ }^{16}$ This has even been reported despite the usual trend of increasing prescribing rate. ${ }^{17} \mathrm{~A}$ second objective therefore was to investigate whether reporting rates of adverse events change with time.

\section{MATERIALS AND METHODS}

\section{Design}

A prospective, observational follow-up study was carried out in 10,008 lansoprazole users in The Netherlands during the first 4 years after marketing from January 1994 until April 1998. ${ }^{15}$ No inclusion or exclusion criteria were applied other than the use of lansoprazole prior to entry into the study. The study design included a population as representative as possible of the general population (in daily practice lansoprazole was prescribed by specialists as well as GPs), a non-interventional design, a clear separation in time between the prescribing of lansoprazole and the inclusion of the patient in the study in order to minimize the influence of the study on prescribing behaviour and evaluation, following SAMM guidelines. ${ }^{18}$ The protocol was approved by the Independent Ethical
Committee of the Utrecht University Hospital. The overall design has been described in detail elsewhere. $^{15}$

\section{Patients}

All patients having used or using lansoprazole were included in the study at the first or any later followup visit after lansoprazole was prescribed. Patients agreed to participate by giving their free informed consent allowing access to all relevant clinical and medication data and storage and analyses of these data. No further selection criteria were considered, meaning that every lansoprazole user independent of diagnosis (labelled or unlabelled, diagnostically tested or not) could enter the study.

\section{Measurements}

The physician collected data at the inclusion visit and at each follow-up visit during lansoprazole therapy with a maximum follow-up of 2 years using standardized questionnaires. The data collection was designed not to influence normal procedures by following routine visits and no preset visit schedule. General characteristics such as age, gender, specialism of evaluating physician, diagnosis of lansoprazole therapy, start date of lansoprazole use and evaluation data were recorded. An adverse event was defined as any undesirable experience including intercurrent events, drug reactions and clinical abnormalities or clinically significant laboratory test abnormalities, occurring during the study. During follow-up, all (adverse) events irrespective of association with lansoprazole therapy were documented, including a description of the event, the date of onset and if available the date the event stopped. Furthermore, the severity of the adverse events was reported as perceived by the physician and classified as mild, moderate, severe or unknown. According to the $\mathrm{ICH} / \mathrm{GCP}$ guidelines, a serious adverse event is defined as an event resulting in death, is life-threatening, requires inpatient hospitalization or prolongation of existing hospitalization, results in persistent or significant disability/incapacity or produces a congenital anomaly/birth defect. ${ }^{19}$ The association of the adverse event with the use of lansoprazole as assessed by the physician was documented as unlikely, possible, probable or unknown. Furthermore, it was stated whether any action was taken due to the adverse event and labelled as, no action, lansoprazole dose reduction or discontinuation, other therapy, other 
action or unknown. Where the same event occurred more than once in one patient, only the first episode was used in the calculations. Labelled adverse events included events described in the product information and unlabelled events included those that were not.

\section{Analysis}

Results were tabulated in absolute values and percentages. Incidence densities were calculated during follow-up as the number of reported adverse events per 1000 patient-months of exposure. The exposure period was defined as the period from the start of therapy until the end of lansoprazole therapy or the end of follow-up when still on therapy. All statistical analyses were performed using SAS statistical package.

\section{RESULTS}

Patient enrollment started in January 1994 following the introduction of lansoprazole in The Netherlands in September 1993 and ended in April 1998. In total 266 specialists and 805 GPs provided respectively 3846 and 6162 patients. In Table 1 general characteristics of the 10,008 patients included in the study are shown, including gender and age distributions. The majority of patients had gastrooesophageal reflux disease as the diagnosis for lansoprazole therapy $(53.6 \%)$ or any ulcer $(14.5 \%)$, whereas in $29.8 \%$ other diagnoses were reported such as 'gastritis', 'dyspepsia' and 'duodenitis'. Most patients were treated with $30 \mathrm{mg} /$ day lansoprazole $(88.6 \%)$, while $5.7 \%$ had a prescription of $\leqslant 15 \mathrm{mg}$ /day and $5.6 \%$ of $\geqslant 60 \mathrm{mg} /$ day.

Of all lansoprazole users $82.6 \%$ reported no adverse events during lansoprazole exposure $(n=8267)$. A total of $11.9 \%$ reported one adverse event, $3.8 \%$ reported two adverse events. During the exposure period, $1.7 \%$ reported three or more adverse events with a mean of 3.4 events per patient. Of patients using $\leqslant 15,30$ and $\geqslant 60 \mathrm{mg}$ /day lansoprazole, $12.0, \quad 17.5$ and $20.8 \%$ respectively reported adverse events. Furthermore, four of the nine patients with an unknown dosage regimen reported adverse events. There was a significant association between daily dose and the reporting of adverse events $(p<0.001)$.

As is shown in Table 2, in total 2539 adverse events were reported. Of all adverse events, $49.4 \%$ were possibly and $26.6 \%$ probably related to the
Table 1 - General characteristics of 10,008 lansoprazole users

\begin{tabular}{|c|c|c|}
\hline \multirow{2}{*}{$\frac{\text { Characteristic }}{\text { Men }}$} & \multicolumn{2}{|c|}{$N=10,008 \%$} \\
\hline & 4864 & 48.6 \\
\hline Women & 5144 & 51.4 \\
\hline \multicolumn{3}{|l|}{ Age (years) } \\
\hline $0-30$ & 660 & 6.6 \\
\hline $30-45$ & 2196 & 21.9 \\
\hline $45-60$ & 3279 & 32.8 \\
\hline $60-75$ & 2768 & 27.7 \\
\hline$>75$ & 1106 & 11.1 \\
\hline \multicolumn{3}{|l|}{ Diagnosis for lansoprazole therapy } \\
\hline $\begin{array}{l}\text { Gastrooesophageal reflux disease } \\
\text { without ulcer }\end{array}$ & 5366 & 53.6 \\
\hline Other* & 2982 & 29.8 \\
\hline $\begin{array}{l}\text { Ulcer without gastrooesophageal } \\
\text { reflux disease }\end{array}$ & 1454 & 14.5 \\
\hline $\begin{array}{l}\text { reflux disease } \\
\text { Ulcer with gastrooesophageal reflex }\end{array}$ & 201 & 2.0 \\
\hline disease & & \\
\hline Unknown & 5 & 0.1 \\
\hline \multicolumn{3}{|l|}{ Daily lansoprazole dose } \\
\hline$\leqslant 15 \mathrm{mg}$ & 566 & 5.7 \\
\hline $30 \mathrm{mg}$ & 8870 & 88.6 \\
\hline$\geqslant 60 \mathrm{mg}$ & 563 & 5.6 \\
\hline Unknown & 9 & 0.0 \\
\hline \multicolumn{3}{|l|}{ Patients reporting adverse events } \\
\hline No adverse events & 8267 & 82.6 \\
\hline One adverse event & 1186 & 11.9 \\
\hline Two adverse events & 381 & 3.8 \\
\hline$>$ Two adverse events & 174 & 1.7 \\
\hline
\end{tabular}

* Other diagnosis of lansoprazole therapy e.g. 'gastritis', 'duodenitis'.

lansoprazole exposure, as assessed by the physician. In a majority of events $(57.8 \%)$ no action was taken, in $5.6 \%$ the lansoprazole dosage was reduced and in $29.0 \%$ lansoprazole therapy was discontinued. According to the physician nearly all adverse events were of either mild $(46.5 \%)$ or moderate $(38.7 \%)$ severity, whereas $14.4 \%$ were characterized as severe adverse events. Most of all the 2539 adverse events concerned the digestive system $(52.1 \%)$, nervous system (17.4\%) and skin and appendices $(9.1 \%)$. In 41 patients $(0.4 \%)$ a series adverse event as defined by the $\mathrm{ICH} / \mathrm{GCP}$ guidelines was reported, including malignant neoplasm $(n=13)$, cardiovascular disease $(n=8)$, rash $(n=2)$, and pneumonia $(n=2) .{ }^{18}$ Of all serious adverse events, $60 \%$ included hospitalizations. Regarding all seri- 
Table 2 - Characteristics of adverse events $(N=2539)$

\begin{tabular}{|c|c|c|}
\hline Characteristic & $N=2539$ & $\%$ \\
\hline \multicolumn{3}{|l|}{ Evaluating physician } \\
\hline General practitioner & 1364 & 53.7 \\
\hline Specialist & 1175 & 46.3 \\
\hline \multicolumn{3}{|l|}{ Severity of adverse events } \\
\hline Mild & 1181 & 46.5 \\
\hline Moderate & 983 & 38.7 \\
\hline Severe & 366 & 14.4 \\
\hline Unknown & 9 & 0.4 \\
\hline \multicolumn{3}{|l|}{$\begin{array}{l}\text { Association of adverse event with lan- } \\
\text { soprazole }\end{array}$} \\
\hline Unlikely & 600 & 23.6 \\
\hline Possible & 1255 & 49.4 \\
\hline Probable & 675 & 26.6 \\
\hline Unknown & 9 & 0.4 \\
\hline \multicolumn{3}{|l|}{ Action taken } \\
\hline None & 1467 & 57.8 \\
\hline Stop therapy & 737 & 29.0 \\
\hline Switch of therapy & 171 & 6.7 \\
\hline Dose reduction & 141 & 5.6 \\
\hline Other action & 4 & 0.2 \\
\hline Unknown & 19 & 0.7 \\
\hline \multicolumn{3}{|l|}{ Specification per body system } \\
\hline Digestive system & 1323 & 52.1 \\
\hline Nervous system & 441 & 17.4 \\
\hline Skin and appendices & 230 & 9.1 \\
\hline Body as a whole & 114 & 4.5 \\
\hline Musculoskeletal system & 94 & 3.7 \\
\hline Psyche & 72 & 2.8 \\
\hline Endocrine/metabolic/nutritional & 71 & 2.8 \\
\hline Other & 194 & 7.6 \\
\hline
\end{tabular}

ous events, no definite causal relationship with lansoprazole was assessed after evaluation.

Distributions of the most frequently $(\geqslant 0.25 \%$ or in other words $\geqslant 25$ events) observed adverse events are listed in Table 3 in percentages of all patients. The most frequently reported adverse events were diarrhoea $(3.7 \%)$, headache $(2.5 \%)$ and nausea $(2.2 \%)$. When compared to available clinical data (expected frequencies), the frequencies of diarrhoea, nausea, constipation and dizziness were similar. ${ }^{3,4}$ The majority of the skin disorders $(1.5 \%)$ included pruritus and/or rash. In our study, headache and vomiting were reported less frequently than expected from data from clinical trials. In patients aged 65 years or over, we found $2.1 \%$ of patients reporting headache versus 1.6 and $4.0 \%$ in clinical trials. ${ }^{3,4}$

To give estimates of 'real-world' frequencies of reported adverse events we calculated incidence densities (IDs). In Table 4, IDs of the top 10 reported events were compared with expected IDs as described in the PEM study. ${ }^{13}$ In our study, 10,008 patients were evaluated during a mean duration of therapy of 3.42 months, in the PEM study 17,329 patients were followed for a mean duration of lansoprazole use of 3.34 months. Our top 10 included seven adverse events which were also included in the top 10 of the PEM study. In addition, we found very similar IDs compared to the PEM data. Only headache and dizziness was slightly more frequently reported in our study compared to the PEM results.

Regarding rarely reported adverse events known from case reports and clinical trials with proton pump inhibitors we found gynaecomastia in two patients (both assessed mild in severity, one not drug related and one possibly drug related). One case of liver disorder, mildly severe and not assessed as lansoprazole related and one moderate severe and possible lansoprazole related liver function abnormality was documented. Acute liver injury and haemolytic anaemia were not reported during this study. A total of 42 patients reported dry mouth. The severity was most frequently mild $(n=24)$, followed by moderate $(n=15)$ and severe $(n=3)$; most often a possible relationship with use of lansoprazole $(n=30)$ was reported, in eight patients a probable relationship and in four others an unlikely relationship with use of the drug. We found 19 patients with acute polyarthralgia, of which 15 were probably or possibly lansoprazole related, four severe and eight requiring a lansoprazole dose reduction or discontinuation.

Ocular events were reported in 25 patients, including abnormal eye sensations $(n=12)$, visual symptoms/complaints $\quad(n=11), \quad$ conjunctivitis $(n=1)$ and symptoms/complaints of the eyelids $(n=1)$. The reported abnormal eye sensations included itching, dryness, swelling, redness and burning/tingling. The visual symptoms/complaints included blurred vision $(n=7)$, temporary blindness/severe vision disorder $(n=2)$, spotting during car driving $(n=1)$ and acute blindness in one patient with a medical history of temporal arteritis and polymyalgia rheumatica $(n=1)$. Of all vision disorders, three events were deemed probably related (i.e. itching, conjunctivitis, other symptoms/complaints of the eyelids) and 13 events pos- 
Table 3 - Frequencies of adverse events $(N \geqslant 25)$ observed in 10,008 lansoprazole users and compared with clinical trial data $(\%)$

\begin{tabular}{|c|c|c|c|c|}
\hline Specification of adverse event & $\begin{array}{c}\text { Observed } \\
\quad N\end{array}$ & $\begin{array}{l}\text { Observed } \\
\%\end{array}$ & $\begin{array}{l}\text { Expected }^{23} \\
\%\end{array}$ & $\begin{array}{l}\text { Expected }^{24} \\
\%\end{array}$ \\
\hline Diarrhoea & 368 & 3.7 & 3.2 & 3.5 \\
\hline Headache & 246 & 2.5 & 4.7 & 8.8 \\
\hline Nausea & 222 & 2.2 & 1.4 & 2.0 \\
\hline Vomiting & 31 & 0.3 & & 1.4 \\
\hline Dizziness & 183 & 1.8 & 1.0 & 1.6 \\
\hline Generalized abdominal pain/cramps & 171 & 1.7 & 2.2 & \\
\hline Flatulence/gas pain/belching & 128 & 1.3 & & \\
\hline Skin disorders & 203 & 2.0 & 1.7 & \\
\hline Constipation & 103 & 1.0 & 1.1 & 1.0 \\
\hline General weakness/tiredness & 50 & 0.5 & $<1$ & \\
\hline $\begin{array}{l}\text { Symptoms/complaints of mouth/tongue/ } \\
\text { lip }\end{array}$ & 99 & 1.0 & & \\
\hline Change in faeces/bowel movements & 77 & 0.8 & & \\
\hline Disturbances of sleep/insomnia & 30 & 0.3 & $<1$ & \\
\hline
\end{tabular}

Table 4-Incidence Densities (ID) of the top 10 of adverse events per 1000 patient-months of use during the total treatment period as observed in 10,008 lansoprazole users and compared with observational data of 17,329 lansoprazole users ${ }^{25}$

\begin{tabular}{lccc}
\hline $\begin{array}{l}\text { Specification of } \\
\text { adverse event }\end{array}$ & $\begin{array}{c}\text { Observed } \\
N\end{array}$ & $\begin{array}{c}\text { Observed } \\
\text { ID per } \\
1000\end{array}$ & $\begin{array}{c}\text { Expected } \\
\text { ID per } \\
1000\end{array}$ \\
\hline Diarrhoea & 368 & 10.7 & 9.9 \\
Headache & 246 & 7.2 & 4.6 \\
Nausea/vomiting & 233 & 6.8 & 5.9 \\
Dizziness & 183 & 5.3 & 2.6 \\
Generalized abdomi- & 171 & 5.0 & 5.7 \\
nal pain/cramps & & & \\
Flatulence/gas & 128 & 3.7 & No info \\
pain/belching & & & \\
Pruritus & 127 & 3.7 & 1.4 \\
Constipation & 103 & 3.0 & 1.8 \\
General weakness/ & 50 & 1.5 & 3.0 \\
tiredness & & & \\
Joint pain & 16 & 0.5 & 3.3 \\
\hline
\end{tabular}

sibly related with the use of lansoprazole (i.e. one patient with blurred vision and 12 patients with abnormal eye sensations), whereas nine events were unlikely to be related to the use of the drug. The incidence density of lansoprazole-related vision disorders was 10.5 per 10,000 person-years (i.e. 2.9 per million treatment days).

There were 1930 probable or possible lan- soprazole-related events of all the 2539 adverse events. Of these 1930 events, 509 were not labelled in the applicable product information for lansoprazole $(26.4 \%)$. Most unlabelled events were reported at a frequency of less than 25 (i.e. less than 2.5 per 1000). However, flatulence/gas and pain/belching was reported 108 times, change in faeces/bowel movements 66 times and symptoms of the mouth such as sensitive tongue and changes in taste 35 times. Of the 509 unlabelled events, 69 were assessed as severe adverse events. Nearly all of these 69 events were reported only once or twice and were of clinical insignificance. There were three clinically significant events of the 69 , namely malignant neoplasm of the oesophagus $(n=3)$, death $(n=2)$ and malignant neoplasm of the prostate $(n=1)$. These six events were reported by the physicians as serious adverse events. ${ }^{19}$ The conclusion after review by experts was that no or no definitive causal relationship between these serious adverse events and treatment with lansoprazole was established. Furthermore, flatulence/gas pain/belching was reported seven times and baldness/losing hair three times and were considered to be probably or possibly lansoprazole related, severe and unlabelled events.

To analyse the influence of time after registration on the reporting of adverse events IDs were calculated for subsequent periods of time. During the first 2 years 5669 patients were followed during 21,084 months of lansoprazole use, whereas in the second period 4339 patients were evaluated during 


\section{ID per 1,000 patient quarters of use}

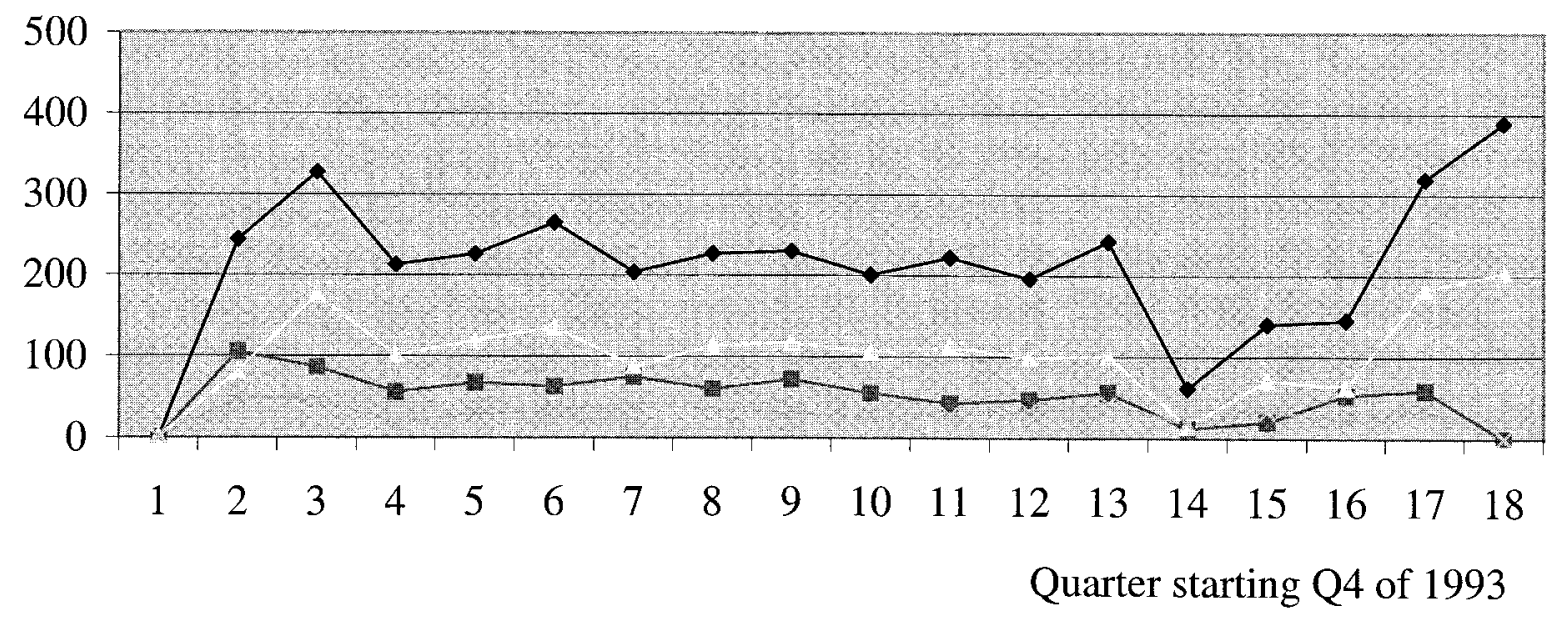

$\rightarrow-$ total $\rightarrow$ probably drug related $\quad$ possibly drug related $*$ severe

Fig. 1 - Incidence Densities of reporting of adverse events $(n=2539)$ for subsequent quarters

13,224 months of use. The ID per 1000 patientmonths of use of any adverse event was 74.0 during the total study period. The ID during the first 2 years after launch (1994-1995) was 78.7 and the ID of the next 2 years was 66.4. Particularly probable drug-related events were less frequently reported in the last 2 years of the study (ID 14.8) compared to the first 2 years (ID 22.7). To analyse the influence of time in more detail, IDs were calculated for subsequent quarters (periods of 3 months) starting at quarter 4 of 1993. As can be seen in Fig. 1, the IDs were high soon after the launch of the drug (quarter 2 and 3) and became stable in the following period. This pattern was even more marked for severe and/or probable lansoprazole-related adverse events. Results of the later quarters (Q14 up to Q18) showed a rapid decrease followed by a quick increase of IDs and were probably artefacts due to a low number of exposure months and a delayed cessation of the study.

\section{DISCUSSION}

The main objective of this study was to assess the safety of lansoprazole in a population composed of users in daily clinical practice and to evaluate the influence of time after registration on the reporting of adverse events.

In clinical trials patients receiving the usual daily dose of $30 \mathrm{mg}$ of lansoprazole reported one or more adverse events in $30.0 \%$ of the study subjects. ${ }^{2}$ In this observational study $17.4 \%$, of the 10,008 patients evaluated, reported one or more adverse events. There was a significant positive association between lansoprazole dose and the reporting of adverse events. It was expected that in this observational study reporting rates were lower compared to clinical trials due to the study design, available information on labelled events etc.

In general, the adverse events during lansoprazole use were mild and self-limiting. It was observed that in $30 \%$ of all adverse events the dose of lansoprazole was stopped and in $6 \%$ the dose was reduced. In nearly $50 \%$ a possible and in one out of four, a probable relationship with the use of lansoprazole was documented by a physician. The reporting rate of serious adverse events of $0.4 \%$ was comparable with the $0.6 \%$ reported in clinical trials. ${ }^{4}$ No serious adverse events related to lansoprazole were observed in the study group.

The overall safety profile of lansoprazole in this 
study was similar to the profile of events in clinical trials and observational studies with lansoprazole and comparative agents. ${ }^{2-4,12,13,20}$ Frequencies were comparable with results from clinical trials, the major exception being that we found lower rates of headache and vomiting. In clinical trials headache was reported in 4.7 and $8.8 \%$ respectively of all patients and in 1.6 and $4.0 \%$ in patients aged 65 years or over using pooled data from international trials. ${ }^{3,4}$ The proportion of patients aged 65 years or over was considerably (three times) higher in our study compared to clinical trials, which may explain the lower rate of reporting headache in our study.

In general we found very similar IDs to those found in the PEM study, although comparisons between results of observational cohort studies are difficult due to multiple possible differences. Possible differences include e.g. diagnoses for which the drug has been used, prescriber, prescribed doses, duration of use, age and sex distributions, publicity, calendar year, initial rate of sale, different pattern of usage of the drug. ${ }^{12,13,21}$

Regarding rare adverse events we found profiles similar to those described in literature..$^{5-11}$ From clinical trials, very few numbers are available about e.g. dry mouth, gynaecomastia and this makes comparisons in reporting rates difficult.

In three patients blindness/severe vision disorder was documented. None of these events were related to lansoprazole use, as assessed by the physician, while according to the WHO database, the ID of drug related blindness/severe vision events was 0.022 per million treatment days. ${ }^{8}$

Garcia Rodriguez investigated ocular events in more detail through a retrospective cohort study in general practice with omeprazole. ${ }^{9} \mathrm{He}$ found no inflammatory lesions, whereas vascular lesions of the eye (e.g. amaurosis fugax) were found with an ID of 2.8 per 10,000 person-years. In our study the ID of any drug-related vision disorder was 10.5 per 10,000 person-years. However, none of these disorders were classified as severe, as assessed by the physician. In addition, patients with certain medical histories e.g. eye disorders, cancer, hypertension, diabetes were excluded from the cohort by Garcia Rodriguez and not by us.

In general practice, it is known that unlabelled drug-related adverse events are more frequently reported compared to labelled events. ${ }^{22}$ There is a selective reporting bias for adverse events with greatest clinical concern. In our study, we found three probable or possible lansoprazole-related and unlabelled events reported over 25 times, namely flatulence/gas and pain/belching $(n=108)$, change in faeces/bowel movements $(n=66)$ and symptoms of the tongue $(n=35)$. Many of these events could result from the treatment as well as from the disease.

Regarding the time trend, we found higher reporting rates soon after the marketing of the drug before falling to a lower stable level. Particularly probable lansoprazole-related adverse events were more frequently reported during the first year after introduction. It is consistent with Weber's theory that the reporting of adverse events with a new drug does not proceed at a uniform rate, but higher spontaneous reporting rates exist soon after the marketing of a drug and this pattern persists before falling to a stable lower level. ${ }^{17}$

\section{KEY POINTS}

- The safety of lansoprazole was evaluated by a 4-year observational follow-up study in daily practice in The Netherlands

- Of 10,008 lansoprazole users $17.4 \%$ reported one or more adverse events. The profile and frequency of reported adverse events were comparable with results from clinical trials and observational studies. The most frequently reported adverse events were respectively diarrhoea, headache, nausea, skin disorders, dizziness and generalized abdominal pain/cramps

- There was no new evidence of rarely reported adverse events

- Furthermore, no drug-related unlabelled adverse events of clinical significance were recorded

- Although the patterns of use of lansoprazole in daily practice deviated to some extent from the specifications in the information leaflet, lansoprazole was found to be highly safe in this large naturally-occurring group of users

In conclusion, this 4-year observational followup study was started to evaluate the safety of lansoprazole in naturally-occurring groups of patients in The Netherlands. GPs (805) and specialists (266) provided a total of 10,008 lansoprazole users with a broad range of (un)registered diagnoses. Of all the patients, $17.4 \%$ reported one or more adverse events. The profile and frequency of reported adverse events was consistent with results from clinical trials and observational studies, whereas the 
proportion of patients aged 65 years or over was considerably (three times) higher in our study compared to clinical trials. The most frequently reported adverse events were respectively diarrhoea, headache, nausea, skin disorders, dizziness and generalized abdominal pain/cramps. In our study, headache and vomiting were reported less frequently than expected from the data from clinical trials. There was no new evidence of rarely reported adverse events. Furthermore, no lansoprazolerelated unlabelled adverse events of clinical significance were recorded.

\section{ACKNOWLEDGEMENTS}

The authors thank Y. J. B. van Megen PhD and C. J. B. Nusteling MSc, of Hoechst Marion Roussel B.V., Hoevelaken, The Netherlands for their valuable contribution to this study and their helpful comments in preparing this manuscript. Grant support for this study by Hoechst Marion Roussel B.V., Hoevelaken, The Netherlands is gratefully acknowledged.

\section{REFERENCES}

1. Prezal 15/30. In Repertorium 98/99: Overzicht van Door het College ter Beoordeling van Geneesmiddelen Geregistreerde Informatieteksten van Farmaceutische Spécialités. Nefarma: 's Gravenhage, Editie 98/99; 24.

2. Langtry HD, Wilde MI. Lansoprazole. An update of its pharmacological properties and clinical efficacy in the management of acid-related disorders. Drugs 1997; 54(3): 473-500.

3. Colin-Jones DG. Safety of lansoprazole. Aliment Pharmacol Ther 1993; 7(Suppl.): 56-60.

4. Colin-Jones DG. Safety of lansoprazole. Br J Clin Pract 1994; 75(Suppl.): 58-66.

5. Teare JP, Spedding C, Whitehead MW, Greenfield SM, Challacombe SJ, Thompson RPH. Omeprazole and dry mouth. Scand J Gastroenterol 1995; 30: $216-$ 218.

6. Garcia Rodriguez LA, Jick H. Risk of gynaecomastia associated with cimetidine, omeprazole, and other antiulcer drugs. BMJ 1994; 308: 503-506.

7. Garcia Rodriguez LA, Wallander M, Stricker BHCh. The risk of acute liver injury associated with cimetidine and other acid-suppressing anti-ulcer drugs. Br J Clin Pharmacol 1997; 43: 183-188.

8. The ADR signals analysis project (ASAP) team: Lindquist M, Pattersson M, Edwards IR et al. Ome- prazole and visual disorders: seeing alternatives. Pharmacoepidemiol Drug Safe 1996; 5: 27-32.

9. Garcia Rodriguez LA, Mannino S, Wallander M, Lindblom B. A cohort study of the ocular safety of anti-ulcer drugs. Br J Clin Pharmacol 1996; 42: $213-$ 216.

10. Schönhöfer PS, Werner B. Ocular damage associated with proton pump inhibitors. BMJ 1997; 314: 1805.

11. Meier CR, Jick H. Omeprazole, H2 blockers and polyarthralgia: case-control study. BMJ 1997; 314: 1283.

12. Mann RD, Wilton LV, Pearce GL, Mackay FJ, Dunn NR. Prescription-Event Monitoring (PEM) in 1996 - A method of non-interventional observational cohort pharmacovigilance. Pharmacoepidemiol Drug Safe 1997; 6(Suppl. 3): S5-S11.

13. Freemantle SN, Pearce GL, Wilton LV, Mackay FJ, Mann RD. The incidence of the most commonly reported events with 40 newly marketed drugs - a study by Prescription-Event Monitoring. Pharmacoepidemiol Drug Safe 1997; 6(Suppl. 1): 1-52.

14. Miwa LJ, Jones JK, Pathiyal A, Hatoum H. Value of epidemiologic studies in determining the true incidence of adverse events. The non-steroidal antiinflammatory drug story. Arch Int Med 1997; 157(18): 2129-2136.

15. Leufkens H, Claessens A, Heerdink E, van Eijk J, Lamers CBHW. A prospective follow-up study of 5,669 users of lansoprazole in daily practice. Aliment Pharmacol Ther 1997; 11: 887-897.

16. Weber JCP. Mathematical models in adverse drug reaction assessment. In Iatrogenic Diseases (3rd edn). D'Arcy PF, Griffin JP (eds). Oxford University Press, Oxford: 1986; 102-107.

17. Weber JCP. Epidemiology of adverse reactions to nonsteroidal antiinflammatory drugs. In Side Effects of Antiinflammatory/Analgesic Drugs, vol. 6. Rainsford KD, Velo G (eds). Raven Press: New York, 1984; $1-7$.

18. Medicines Control Agency, Committee on Safety of Medicines, Royal College of General Practitioners, British Medical Association and Association of the British Pharmaceutical Industry (November 1993). Guidelines for company-sponsored safety assessment of marketed medicines (SAMM). Br J Clin Pharmacol 1994; 38: 95-97.

19. Clinical Safety Data Management, Definitions and Standards for Expedited Reporting. ICH Harmonised Tripartite Guideline. Recommended for Adoption at Step 4 of the ICH Process on 27 October 1994 by the ICH Steering Committee.

20. Freston JW, Rose PA, Heller CA, Haber M, Jennings D. Safety profile of lansoprazole. The US Clinical Trial Experience. Drug Safety 1999; 20: 195-205.

21. Speirs CJ. Prescription-related adverse reaction profiles and their use in risk-benefit analysis. In Iatrogenic Diseases (3rd edn). D'Arcy PF, Griffin JP (eds). Oxford University Press, Oxford: 1986; 93-101. 
22. Martin RM, Kapoor KV, Wilton LV, Mann RD. Underreporting of suspected adverse drug reactions to newly marketed ('black triangle') drugs in general practice: observational study. BMJ 1998; 317: 119120.

23. Colin-Jones DG. Safety of lansoprazole. Aliment Pharmacol Ther 1993; 7(Suppl.): 56-60.
24. Colin-Jones DG. Safety of lansoprazole. Br J Clin Pract 1994; 75(Suppl.): 58-66.

25. Freemantle SN, Pearce GL, Wilton LV, Mackay FJ, Mann RD. The incidence of the most commonly reported events with 40 newly marketed drugs - a study by Prescription-Event Monitoring. Pharmacoepidemiol Drug Safe 1997; 6(Suppl.): 1-52. 